\title{
"Não é nada, não vejo nada, não ouço nada" - Franz Kafka sobre a construção de nossa indiferença moral
}

\author{
PABLO BAPTISTA RODRIGUES *
}

\begin{abstract}
RESUMO Meu ensaio tem como objetivo tecer considerações literárias e filosóficas sobre as condições ético-políticas das relações sociais nas sociedades contemporâneas. Em especial o lugar da "indiferença” como "afeto político" na elaboração e estabelecimento da atual ordem social. Esta leitura será realizada a partir do conto “O cavaleiro do balde” de Franz Kafka (KAFKA, 2011). Encontramos na narrativa kafkiana o personagem cavaleiro do balde que se depara com a dura realidade de não ter mais o carvão diário para enfrentar o inverno. Guiado pela necessidade nosso personagem vai até a casa do carvoeiro e implora por um pouco de carvão. Diante dessa porta, parecido como o homem que está "Diante da lei” (KAFKA, 2011), o cavaleiro do balde não é sequer convidado a entrar, ele não é visto e nem ouvido: "Você é malvada! Pedi uma pá do pior carvão e você não me deu” (KAFKA, 2011). A aproximação de nosso autor como o pensamento de Hannah Arendt (HARENDT, 1999) e Zygmunt Bauman (BAUMAN, 2014) é estratégica para refletir naquilo que ambos os pensadores propuseram por meio de seus trabalhos. No caso de Arendt o conceito de "banalidade do mal" que passa a designar, entre outras coisas, uma nova forma de leitura para antiga relação “bem-mal”. E a “cegueira moral”, por Bauman, característica da sociedade líquida.
\end{abstract}

PALAVRAS-ChAVE Franz Kafka; Indiferença; Política.

* Mestrando do PPG-Ciência da Literatura da UFRJ

Bolsista CNPq 


\section{CONSIDERAÇÕES NECESSÁRIAS}

Quando pensei em me apresentar pela segunda vez na Semana de Filosofia dos Alunos de Pós-graduação da PUC-RJ, SAF 2018, me senti convidado e entusiasmado a lançar aos meus colegas de pós-graduação uma inquietação que me surgiu a partir das minhas vivências mais particulares e compartilhadas na leitura do texto de Franz Kafka. Este texto tem uma tonalidade. A tentativa de colocar em cena a questão da indiferença coletiva como afeto político contemporâneo.

Agradeço está oportunidade aos colegas Carlota Ferreira, Deysielle Chagas, Felipe Amancio, Larissa Primo, Patrícia Matias, Rodrigo Viana e Taigon Gonçalves e tantos outros que possibilitaram que a SAF 2018 ocorresse e me permitisse a experimentação de ideias e afetos. Para mim foi um imenso prazer estar mais uma vez na PUC-RJ, na Sala Leandro Konder, um dos importantes leitores de Franz Kafka com todos os colegas. Vocês não sabem o que isso significou para mim. Foi o meu segundo ano a apresentar na SAF, e confesso que naquela primeira vez, em 2017, me senti profundamente enriquecido com uma forma série e afetuosa de se construir a universidade brasileira. Colegas que no final vieram até mim, indicaram textos e autores, num gesto de amizade e companheirismo. Aquela emoção foi a primeira vivida em uma semana de pós-graduação. No momento de encerramento de minha pesquisa como mestrando em Teoria literária pelo Programa de Pós-graduação em Ciência da Literatura da UFRJ, considerei encerrar um ciclo pessoal voltando a PUC-RJ e a SAF 2018. Foi nesse amor à filosofia que compartilhei com o auditório algumas ideias a respeito da indiferença contemporânea.

\section{INTRODUÇÃO}

Minha comunicação tem o seguinte título “Não é nada, não vejo nada, não ouço nada - Franz Kafka sobre a construção de nossa indiferença moral”. Após uma longa conversa com alguns amigos, percebi que nossos relacionamentos tinham chegado ao fim e se caminhavam para um outro terreno, para mim completamente novo. Algo tinha morrido e diante do meu desespero emocional uma constatação me veio após um pe- 
ríodo de reflexão, que deveria assumir a indiferença como emoção necessária à minha sobrevivência emocional. Impregnado por esse germe "academicus", me coloquei numa espécie de investigação literária e filosófica sobre o lugar da indiferença como uma espécie de novo afeto político para o gerenciamento do corpo social.

Numa busca simples nos mecanismos de busca da internet descobrimos que a taxa de desemprego fluminense chega a 15\%. O portal UOL noticiou que o "RJ [Rio de Janeiro] viu número de desempregado subir $157 \%$ em 3 anos". ${ }^{1}$ Já sobre a morte de mulheres o jornal O Globo registra crescimento de $63 \%,{ }^{2} \mathrm{em} 2017$, no número de feminicídios em nosso estado. Sobre a segurança pública estadual o jornal Extra nos informa que crimes como assassinatos e roubos de cargas crescem desde o primeiro mês de intervenção federal. ${ }^{3}$ Sobre a população LGBTQI+ no Brasil, a Agência Brasil relata que o número de assassinatos de travestis e transexuais é o maior em 10 anos. ${ }^{4} \mathrm{~A}$ mesma agência informa que em 2016 aumentou cerca de 12\% o número de refugiados no Brasil. ${ }^{5}$ Poderia dizer ainda, sobre a situação das comunidades indígenas que sofrem as especulações de suas terras, a situação do genocídio negro no brasil, o aumento do caso de intolerância religiosa em áreas dominas pelo tráfico, o agronegócio....

O que podemos fazer diante de tantas informações que recebemos ao longo de alguns minutos diante da TV? Ou quando, sem a nossa vontade, recebemos as notícias por meio de mensagens em nossos e-mails, e em nossos aparelhos celulares as notificações surgem em nossas contas do Facebook, Twitter, Instagram e Whatsapp. En-

1 UOL. Em crise, RJ viu número de desempregados subir 157\% em 3 anos. UOL Economia, 2018. Disponível em: <https://economia.uol.com.br/empregos-e-carreiras/noticias/redacao/2018/02/23/ desemprego-pnad-continua-trimestre-janeiro-ibge.htm>. Último acesso em: 16 agosto 2018.

2 O GLOBO. Número de registros de feminicídios no Rio cresceu 63\% em 2017. O Globo Rio, 2018. Disponível em: $<$ https://oglobo.globo.com/rio/numero-de-registros-de-feminicidios-no-rio-cresceu-63-em-2017-22265400>. Último acesso em: 16 Agosto 2018.

3 EXTRA. Crimes como assassinatos e roubos de cargas crescem no primeiro mês de intervenção federal no Rio. Extra, 2018. Disponível em: <https://extra.globo.com/casos-de-policia/crimes-como-as$\underline{\text { sassinatos-roubos-de-cargas-crescem-no-primeiro-mes-de-intervencao-federal-no-rio-22510124. }}$ html $>$. Último acesso em: 16 Agosto 2018.

4 MARTINS, H. Número de assassinatos de travestis e transexuais é o maior em 10 anos no Brasil. Agência Brasil, 2018. Disponível em: <http://agenciabrasil.ebc.com.br/geral/noticia/2018-01/assassinatos-de-travestis-e-transexuais-e-o-maior-em-dez-anos-no-brasil >. Último acesso em: 16 agosto 2018.

5 VERDÉLIO, A. Número de refugiados reconhecidos sobe 12\% no Brasil em 2016. Agência Brasil, 2017. Disponivel em: <http://agenciabrasil.ebc.com.br/direitos-humanos/noticia/2017-06/numero-de-refugiados-reconhecidos-sobre-12-no-brasil-em-2016>. Último acesso em: 16 Agosto 2018. 
quanto me preparava para SAF 2018 um querido ex-aluno, Lucas Araujo, me enviou a notícia do lançamento do clipe “This America”, 6 de Childish Gambino, pseudônimo de Donald Glover, me convocando a oferecer-lhe uma opinião, uma análise, no que não fui capaz, daquele vídeo que buscou ser uma canção antirracista, e forma de denúncia a profunda história da violência americana no tratamento do corpo negro. No dia 9 de junho, às 18h, na Capela Ecumênica da UERJ, a comunidade acadêmica prestava suas homenagens a Matheusa Passarelli, desaparecida e assassinada. O que dizer da ferida ainda aberta após 150 dias da morte da vereadora do PSOL, Marielle Franco, e de seu motorista, Anderson Pedro Gomes, no dia 14 de março de 2018.

\section{UMA TRADIÇÃO LITERÁRIA DO “SE IMPORTAR”}

Em nossa tradição literária eu posso recorrer a alguns livros monumentais de nossa literatura para afirmar que desde a Grécia de Homero e Sófocles o tema do "se importar com seus semelhantes" se colocou presente como questão basilar para os gregos. Há de se lembrar nos textos da Odisseia, em que o personagem Eurínomo "Nunca deixava, porém, de chorar pela Morte daquele". ${ }^{7}$ Telêmaco após a fala na assembleia "indignado; e rompendo num pranto copioso,/ o cetro atira no chão./ Todo o povo de dor é tomado". ${ }^{8}$ E são muitos os momentos de choro do próprio Odisseu. Pelos tripulantes perdidos. Pela lembrança da casa. Pelo regresso à Ítaca.

Em Antígona, de Sófocles, no prólogo lemos o embate entre Antígona e Ismênia sobre como enterrar seu irmão Polinices, tido como traidor pelo tio Creonte. Eis a sua voz: "Sim, a esse irmão que é meu e teu [Ismênia], ainda que o não queiras. Não me acusarão de o ter atraiçoado. [...] A ele não lhe é dado separar-me dos meus". ${ }^{9}$ Antígona indo contra as leis e os costumes da polis, reivindica o direito de não ser indiferente a morte de seu semelhante, ainda que o Estado com todos os seus mecanismos a proíba. Tanta dor. Tanto amor. Antígona. Hoje ainda, milhares de familiares reivindicam o direito de sepultar seus entes queridos, mortos ou desaparecidos, frutos da crueldade

6 GLOVER, D. Childish Gambino - This Is America (Official Video). Youtube, 2018. Disponivel em: <https://www.youtube.com/watch?v=VYOjWnS4cMY>. Acesso em: 16 agosto 2017.

7 HOMERO, Odisseia, p. 46.

8 HOMERO, Odisseia, p. 47.

9 SÓFOCLES, Antigona, p. 31. 
do aparato e fracasso de nosso Estado. Só na Baixada Fluminense, (notícias de 2015) quatro pessoas desaparecem por dia, em média. ${ }^{10}$

Lembremos também na tradição judaico-cristã lemos a parábola do Bom Samaritano contada pelo Cristo no evangelho segundo Lucas. Um homem atacado por assaltantes, é espancado e deixado na estrada para morrer. Três personagens passam diante deste homem e apenas um, reconhecendo estar ali um semelhante, decide parar e lhe presta assistência. O sacerdote o rejeita. O levita o rejeita. Porém, o samaritano, "que ia de viagem chegou ao pé dele e, vendo-o, moveu-se de íntima compaixão” ${ }^{11}$.

Poderia aqui dar mais exemplos. Em especial, um recorte mais preciso que é do início da nossa modernidade literária com D. Quixote, de Miguel de Cervantes. O Cavaleiro da Triste Figura com a sua loucura, que também é sanidade, busca resolver as injustiças do mundo presentes em seu caminho. Dom Quixote, vendo um menino que apanhava diz para o agressor: "Descortês cavaleiro, não fica bem espancar quem não pode se defender; montai vosso cavalo e empunhai vossa lança - que eu vos farei saber que é coisa de covarde o que estais fazendo". A cena se desenvolve e uma sutil resposta é dada pelo jovem agredido: "Meu amo [que era o agressor] não é cavaleiro nem recebem ordem de cavalaria nenhuma; é Juan Papudo, o rico, morador de Quintaar". ${ }^{12}$ No passo de D. Quixote responde: “Isso pouco importa”. Ou seja, para Quixote não é possível ser indiferente. Como diz Carlos Fuentes: "O conceito quixotesco de justiça é um conceito de amor. E através do amor, a justiça abstrata de D. Quixote adquire plenitude". ${ }^{13}$ Falemos então de outro cavaleiro, que leva ao extremo a modernidade literária quixotesca. O “Cavaleiro do Balde”, de Franz Kafka.

\section{FRANZ KAFKA: SOBRE NOSSA INDIFERENÇA MORAL}

Escrito no inverno de 1916, instalado na rua dos Alquimistas, em Praga, mesmo lugar em que redigiu o livro O médico rural o conto "O cavaleiro do balde" foi excluído de

10 ZUACO, P. Baixada Fluminense tem quatro desaparecidos a cada dia. Extra, 2017. Disponivel em: $<$ https://extra.globo.com/casos-de-policia/baixada-fluminense-tem-quatro-desaparecidos-cada-dia-16269597.html>. Acesso em: 16 Agosto 2018.

11 Bíblia, p. 1527.

12 CERVANTES, Dom Quixote, p. 69.

13 FUENTES, Cervantes ou a crítica da leitura, p. 64-65. 
um projeto que se chamaria “As pequenas narrativas", todas com temática do cavalo e cavalaria. Os textos nascem para o público, no natal de 1921, no suplemento Prager Presse. Temos no conto uma passagem urbana gelada, a pobreza de um cavaleiro que cavalga em seu balde vazio em busca de carvão e a maledicência da senhora carvoeira. O conto tem apenas três páginas em tradução de Modesto Carone. Poderia ser dividido em Momento 1) A constatação da falta de carvão e a cavalgada no balde rumo a casa do carvoeiro. Momento 2) As súplicas não atendidas diante da casa do carvoeiro. E por fim, o Momento 3) A morte de nosso cavaleiro.

Diz o nosso personagem principal: “tenho, portanto, de cavalgar nítido entre os dois e no meio buscar ajuda do carvoeiro; Mas ele já está insensível aos meus pedidos costumeiros; é necessário provar-lhe com precisão absoluta que já não tenho uma só migalha de carvão e que sendo assim ele significa para mim o próprio sol no firmamento". Temos aqui, a chave de compreensão desse relacionamento triangular: O carvoeiro - O cavaleiro - E a senhora carvoeira. Diante de sua necessidade costumeira e seus inúmero pedidos, temos uma relação baseada na insensibilidade.

Nosso personagem então, denúncia uma espécie de moral do “Não matarás”, que fará com que o senhor carvoeiro decida pelo bem e amor ao pobre cavaleiro do balde. Que gasta suas últimas energias a provar seu estado de miséria. Confiando nessa moral que impelirá o carvoeiro a fazer o bem acima de todas as coisas o Cavaleiro do Balde suplica na porta do carvoeiro. Com seu balde vazio, mais belo do que camelos, nosso cavaleiro kafkiano da triste figura sobe ruma a esperança.

Pela rua dura de gelo ele avança e ao chegar diante da abóbada do depósito do carvoeiro clama debaixo do gelo e em volto de fumaça: "Por favor, carvoeiro, me dê um pouco de carvão. Meu balde já está vazio que posso cavalgar nele. Seja bom. Assim que puder eu pago”. O carvoeiro ainda pergunta: “Estou ouvindo bem? Estou ouvindo direito? Um freguês?”, indo de encontro a voz do cavaleiro. Ao passo que sua esposa responde: "Não estou ouvindo absolutamente nada".

Um certo mal-estar se coloca na casa, pois o carvoeiro insiste em dizer que algo o chama lá fora. Algo está impelindo sua moral a ir à porta. Novamente sua esposa diz: “O que há com você, homem? Não é ninguém, a rua está vazia, toda nossa freguesia está servida, podemos fechar a loja durante dias e descansar". Mas ainda insiste o carvoeiro e para solucionar de vez esse impasse a mulher vai até a porta. Lá nosso cava- 
leiro diz: “Senhora carvoeira! Respeitosa saudação: só uma pá de carvão, bem aqui no balde; eu mesmo o levou para casa, uma pá do pior carvão. Evidentemente pago tudo, mas não agora, não agora”. O que ele quer, então? Brada o Carvoeiro; “Nada. Grita de volta a mulher. Não é nada, não vejo nada, não ouço nada”. E com isso nosso cavaleiro ascende as regiões das montanhas geladas e se perde para nunca mais.

Ronaldo Lima Lins escrevendo em A indiferença pós-moderna, ${ }^{14}$ nos revela que é no dia a dia da cidade, no pegar ônibus, ou o metrô, nessa aparente lógica tranquila, que o nosso “espantar-se com”, desaparece. Como se assumir a vivência do dia a dia gerasse em nós o desastre dos ataques que continuamente sofremos. A violência nos prende em seu enredo de solidão e na influência na escolha e aceitação dos dispositivos de segurança como carros, condomínios fechados, grades, muros; reeducando com isso o nosso olhar.

É bem certo, que todas as épocas apresentaram variações na sua indiferença. Nunca na história parte da humanidade desfrutou de um avanço tecnológico como o que vivemos. Mas a indiferença pós-moderna, cito Lima Lins: “não impede que a produção se acelere e que a indústria atire novas invenções no mercado. Manifesta-se entre os indivíduos. Não parece grave de início, como se não limitasse nossas ambições. Mas não desaparece. Lembra uma doença. Age nos costumes e se infiltra no presente: no egoísmo, na violência dos bairros, na calma do abismo social, nas artes, na política”. Porque para o homem que sofria no centro de Duque de Caxias, Baixada Fluminense, em uma terça-feira qualquer, fechamos os olhos e seguimos em nossas compras desnecessárias. Ele não é nosso parente, e em muitos casos, ainda que fosse, em nada também nos comoveria. Entretanto, não se consegue erguer fronteiras impenetráveis quando se busca olhar a condição humana. O ato de ver impõe as vezes uma dor insuportável. E num gesto de autodefesa, preferimos substituir a realidade brutal pela fantasia, o equilíbrio das forças antagônicas, pela versão ideológica apaziguadora, mesmo quando sentimos, que todo esse mecanismo se trate de um grande engano.

Mas de que modo se escreve a indiferença? Podemos rascunhar uma possibilidade de compreensão ao seguir o percurso dos gregos, cristãos medievais e o início da modernidade e o período iluminista, para pensar uma fé ora na pólis, em Deus, e na razão,

14 LINS, A indiferença pós-moderna. 
para proporcionar ao corpo social a possibilidade de organização e equilíbrio. Entretanto, não contávamos com o desenvolvimento de nossa individualidade.

Nossa sociedade indiferente pode ser resultado da profunda crise de nosso sistema democrático. Isso porque, a democracia teria como objetivo particular não permitir que tomemos o caminhado exagerado que nossa individualidade. No seu fracasso o sistema democrático não é mais capaz de mostrar ao eu a importância das relações coletivas, que são o uma espécie de acervo das nossas atitudes e influenciadoras da forma pela qual nos tornamos mais ou menos engajados. O eu já não mais dividido, mas único, exclusivo, perde a noção da realidade e nos arrasta para a miséria.

O problema se coloca, portanto, não apenas no ruir da nossa experiência democrática, mas sim isso posto como um projeto da organização social. Hannah Arendt ${ }^{15} \mathrm{e}$ Zygmunt Bauman ${ }^{16}$ são dois autores que se colocam na denúncia da nossa indiferença pós-moderna ao longo de suas atividades intelectuais. Ao testemunhar o julgamento de Eichmann, Arendt se estabelece uma ligação entre a falta de imaginação e a banalidade do mal; o fato de um indivíduo ser capaz de cometer crimes atrozes como um executante, sem pensar. O que constata é a criação de uma nova mentalidade que influência na seleção da tomada de atitudes.

Aprofundando as considerações de Arendt, Bauman e Donski afirmam que "O mal não está confinado às guerras ou às ideologias totalitárias. Hoje ele se revela com mais frequência quando deixamos de reagir ao sofrimento de outra pessoa, quando nos recusamos a compreender os outros, quando somos insensíveis e evitamos o olhar ético silencioso". Nesse sentido, o pequeno conto de Franz Kafka, pode ser sintoma de uma sociedade em crise. Há algo de novo em nossa capacidade de conviver e na viabilidade da comunidade humana. Nossa indiferença social, cito novamente os dois autores de Cegueira moral,

inclui nosso esquecimento deliberado do Outro, a recusa proposital em reconhecer e admitir um ser humano de outro tipo, ao mesmo tempo que descartamos alguém vivo, real, e que está fazendo e dizendo alguma coisa bem ao nosso lado - tudo em nome de fabricar um “amigo" no Facebook distinto de você e

15 ARENDT, Cegueira moral.

16 BAUMAN e DONSKIS, Cegueira moral. 
que talvez viva em outra realidade semiótica. Nessa lista também se encontra a alienação, ao mesmo tempo que se simula a amizade. ${ }^{17}$

Assumir a indiferença a partir de Bauman e Arendt é de certo modo extremamente angustiante. Isso porque, nossas roupas, o quanto ganhamos, os bares e lojas que frequentamos, os livros que lemos e as comunicações que proferimos, nos aproxima ao longe, é claro, daquele homem dentro da cabine de vidro de altura mediana, magro, meia-idade, quase calvo, dentes tortos e olhos míopes, Adolf Eichmann.

Na micropolítica do dia a dia, estamos a fechar os olhos aos que nos auxiliam no elevador, o corpo de trabalhadores que nos preparam o prédio para nosso encontro da $\mathrm{SAF}$, de que o motorista que nos leva ao local desejado sorri e emudece. Cito mais uma vez Ronaldo Lima Lins:

A literatura da indiferença escreve contra a indiferença. É uma forma de pôr em prática uma teoria - resistir. Como sinal, opera no espaço da interioridade, região obscurecida pelo excesso de luminosidade, na confusão pós-moderna, mas ainda lá, um ponto de expectativa no qual a hipótese da liberdade permanece viva, à espera de atitudes. ${ }^{18}$

\section{REFERÊNCIAS BIBLIOGRÁFICAS}

ANDERS, G. Kafka: pró \& contra. Tradução de Modesto Carone. São Paulo: CosacNaify, 2007.

ARENDT, H. Eichmann em Jerusalém. São Paulo : Companhia das Letras , 1999.

ARENDT, H. Compreender: formação, exílio e totalitarismo. Tradução de Denise Bottmann. São Paulo, Belo Horizonte: Companhia das Letras, EditoraUFMG, 2008.

BAUMAN, Z.; DONSKIS, L. Cegueira moral: a perdade da sensibilidade na modernidade liquída. Tradução de Carlos Alberto Medeiros. Rio de Janeiro : Zahar, 2014. (ePub).

BÍBLIA. Tradução de João Ferreira de Almeida. Rio de Janeiro: CPAD, 2007.

CARONE, M. Lição de Kafka. São Paulo: Companhia das Letras, oooo.

17 BAUMAN e DONSKIS, Cegueira moral, p. 14.

18 LINS, A indiferença pós-moderna, p. 125. 
CERVANTES, M. D. Dom Quixote. Tradução de Ernani Ssó. São Paulo: Comapanhia das Letras, 2012.

EXTRA. Crimes como assassinatos e roubos de cargas crescem no primeiro mês de intervenção federal no Rio. Extra, 2018. Disponivel em: <https://extra.globo.com/casos-de-policia/crimes-como-assassinatos-roubos-de-cargas-crescem-no-primeiro-mes-de-intervencao-federal-no-rio-22510124.html>. Acesso em: 16 Agosto 2018.

FRY, K. A. Compreender Hannah Arendt. Tradução de Paulo Ferreira Valério. Rio de Janeiro: Vozes, 2010.

FUENTES, C. Cervantes ou a crítica da leitura. In: CERVANTES, M. D. Dom Quixote. Tradução de Sérgio Molina. São Paulo: Nova Aguilar, 2015. p. 53-66.

GLOVER, D. Childish Gambino - This Is America (Official Video). Youtube, 2018. Disponivel em: <https://www.youtube.com/watch?v=VYOjWnS4cMY>. Acesso em: 16 agosto 2017 .

HOMERO. Odisseia. Tradução de Carlos Aberto Nunes. Rio de Janeiro: Nova Fronteira, 2015 .

KAFKA, F. Um médico rural. Tradução de Modesto Carone. São Paulo: Companhia das Letras, 1999.

KAFKA, F. O processo. Tradução de Modesto Carone. Rio de Janeiro, São Paulo: O Globo, Folha de S. Paulo, 2003.

KAFKA, F. Essencial Franz Kafka. Tradução de Modesto Carone. São Paulo: Companhia das Letras, 2011.

LINS, R. L. A indiferença pós-moderna. Rio de Janeiro: Editora da UFRJ, 2006.

MARTINS, H. Número de assassinatos de travestis e transexuais é o maior em 10 anos no Brasil. Agência Brasil, 2018. Disponivel em: <http://agenciabrasil.ebc.com.br/geral/ noticia/2018-01/assassinatos-de-travestis-e-transexuais-e-o-maior-em-dez-anos-no-brasil>. Acesso em: 16 agosto 2018.

O GLOBO. Número de registros de feminicídios no Rio cresceu 63\% em 2017. O Globo Rio, 2018. Disponivel em: <https://oglobo.globo.com/rio/numero-de-registros-de-feminicidios-no-rio-cresceu-63-em-2017-22265400>. Acesso em: 16 Agosto 2018. 
SÓFOCLES. Antígona. Tradução de Maria Helena da Rocha Pereira. Brasília: Editora $\mathrm{UnB}$.

UOL. Em crise, RJ viu número de desempregados subir 157\% em 3 anos. UOL Economia, 2018. Disponivel em: <https:/economia.uol.com.br/empregos-e-carreiras/noticias/redacao/2018/02/23/desemprego-pnad-continua-trimestre-janeiro-ibge.htm>. Acesso em: 16 agosto 2018 .

VERDÉLIO, A. Número de refugiados reconhecidos sobe 12\% no Brasil em 2016. Agência Brasil, 2017. Disponivel em: <http://agenciabrasil.ebc.com.br/direitos-humanos/noticia/2017-06/numero-de-refugiados-reconhecidos-sobre-12-no-brasil-em-2016>. Acesso em: 16 Agosto 2018.

ZUACO, P. Baixada Fluminense tem quatro desaparecidos a cada dia. Extra, 2017. Disponivel em: <https://extra.globo.com/casos-de-policia/baixada-fluminense-tem-quatro-desaparecidos-cada-dia-16269597.html>. Acesso em: 16 Agosto 2018. 